\title{
Reforma Agraria en Chile, ¿Palimpsesto de otra ruralidad? Reflexiones y propuestas
}

\author{
Marcel Thezá Manríquez \\ Centro de Estudios del Desarrollo Regional y Políticas Públicas - CEDER, \\ Universidad de Los Lagos, Santiago, Chile. \\ Email: marcel.theza@ulagos.cl
}

\section{Daniel Flores Cáceres}

Centro de Estudios del Desarrollo Regional y Políticas Públicas - CEDER,

Universidad de Los Lagos, Santiago, Chile.

Email: danielflorescaceres@gmail.com

\section{Daniella Gac Jiménez}

Centro de Estudios del Desarrollo Regional y Políticas Públicas - CEDER, Universidad de Los Lagos, Santiago, Chile.

Email: daniella.gac@ulagos.cl

\begin{abstract}
Resumen $^{1}$ : El presente artículo aborda e interroga al proceso de la Reforma Agraria chilena a partir de las hipótesis que comúnmente se esgrimen, en cuanto a que esta Reforma fue precisamente la consecuencia de un abanico de urgencias de modernización y desarrollo capitalista, lo cual se constata en la mayor parte de los países de América Latina. A partir de este enfoque se observa que el aspecto central de esta Reforma fue la necesidad de apurar la modernización productiva del sector agrícola, así como enfrentar los desafíos de reconfiguración de las relaciones de poder dentro de los espacios sociales rurales. Bajo estas consignas, el presente artículo sugiere que el proceso observado muestra una interesante lógica de "palimpsesto”, donde las fronteras del cambio histórico son más bien imprecisas, en cuanto no terminan por definir realidades que aún continúan en tensión; lo anterior desde un perspectiva productiva, social y cultural.
\end{abstract} mas sociales

Palabras clave: Reforma agraria, campesinado, producción, cultura, siste-

\section{Chilean Agrarian Reform: Palimpsest of Another Rurality? Reflections and Proposals}

\begin{abstract}
This paper deals with and questions the process of the Chilean agricultural reform from the commonly used hypothesis about this reform being precisely the consequence of a variety of emergencies for modernization and capitalist development, which is observed in most part of Latin American countries.From this approach, we observe that the central focus of this reform was the need to rush the productive modernization of the agriculture sector, as well as facing the challenges of reconfiguration of the power relations within the rural social spaces. Taking into
\end{abstract}


consideration those elements, this paper suggests that the process observed shows an interesting logic of "palimpsest", where the limits of history change are rather vague, as far as they do not end in defining realities that still exist in tension; from a productive, social and cultural perspective.

Keywords: land reform, peasantry, culture, social systems, production

\section{Reforma agrária no Chile, ¿palimpsesto outraruralidade? reflexões e propostas}

Resumo: Este artigo endereços e interroga o processo de reforma agrária chilena de hipótesescomumenteexercem, em que esta reforma foi precisamente a consequência de umasérie de modernização de emergência e desenvolvimento capitalista, que é afirmado na maioria dos países da América Latina. A partir destaabordagemmostra que o aspecto central desta reforma foi a necessidade de acelerar a modernização do setor de produção agrícola e enfrentar os desafios de reconfigurar as relações de poder dentro dos espaçossociaisrurais. Nestas slogans, este artigo sugere que o processo observado mostrauma lógica interessante "palimpsesto", onde as fronteiras da mudança histórica são bastante vagos, como eles nãoacabam por definir realidades que aindaestãoemtensão; acima do ponto de vista produtivo, social e cultural.

Palavras-chave: reforma, campesinato, produção, cultura, sistemas sociaisagrários

\section{Introducción}

Hace aproximadamente 10 años, también en el contexto de la conmemoración del proceso de Reforma Agraria en Chile, el Programa de las Naciones Unidas, PNUD, presentó el Informe de Desarrollo Humano sobre el mundo rural (PNUD, 2008). Dentro de este informe se consultó - en una encuesta levantada específicamente en zonas rurales - tanto por la evaluación como por la memoria de este periodo al cual normalmente se le asigna una connotación histórica de gran relevancia y de profundo impacto para sus generaciones futuras. Los resultados de las preguntas aplicadas no dejaron de ser paradojales. Si bien el 58\% de los encuestados respondió "haber escuchado hablar de la Reforma Agraria”, solo el 40\% del grupo socioeconómico más bajo, y el 30\% de los jóvenes de entre 18 y 29 años, respondieron afirmativamente a esta pregunta; a saber, que habían escuchado hablar de esta etapa de la historia de Chile. De igual forma, del grupo que escuchó hablar de la Reforma Agraria solo el 50\% planteó que fue un hecho más bien positivo para el país, mientras que un 36\% señaló que fue un hecho más bien negativo. El resto, un 14\%, declaró no tener opinión o no saber al respecto (PNUD-Chile, 2008, pp. 44-45).

En consecuencia, estos datos nos hablan de una evidente fragilidad y complejidad de la memoria frente a este hecho fundamental en nuestra historia; fragilidad y complejidad que es preciso contribuir a comprender y 
a precisar. Hoy, en el marco de un nuevo aniversario - cincuenta años de la promulgación de la Ley 16.640 sobre Reforma Agraria en Chile (Biblioteca del Congreso Nacional de Chile, 1965) - qué duda cabe sobre el impacto de esta Reforma en la escritura, en la estructuración del relato y en la conformación de nuestra actual modernidad. Sin embargo, y a la luz de las estadísticas presentadas, es de toda evidencia que, a pesar de su relevancia simbólica como hecho clave de la historia nacional, hoy nos vemos obligados a complejizar las dimensiones de este impacto para comprender cómo se siguió "re-escribiendo" esta historia y qué aspectos permanentes persisten en la actualidad.

Por ello, la hipótesis medular que sostiene este artículo es que en la historia del mundo rural chileno confluyen diversos vestigios de a lo menos dos escrituras distintas y anteriores que se van yuxtaponiendo, y que, en este contexto, de cierta forma hacen convivir la Hacienda con la propia Reforma Agraria, adquiriendo aquello precisamente las características de un palimpsesto. Si la historia es émula del tiempo y depósito de sus acciones, al decir de Cervantes (Cervantes Saavedra, 1871), es porque de ella se desprende una continuidad. Precisamente esta continuidad, en el caso específico de la Reforma Agraria, termina leyéndose más bien como una insinuación; lo mismo que en los viejos pergaminos reutilizados producían las anteriores escrituras sobre las nuevas. Lo anterior no solo se produciría por la poca incumbencia en la memoria de sus herederos directos - que son formalmente los habitantes del mundo rural - como sugiere el hallazgo del Informe del PNUD Rural (2008); sino fundamentalmente por los propios trazos que la trascendencia de ambos periodos - la Hacienda y la Reforma nos han legado.

Si creemos que la Historia se repite una vez como tragedia y la otra como farsa, podríamos plantear que entre la Hacienda y la Reforma existe un juego de escrituras espejo. Así, frente a la improductividad de la Hacienda, aparece la eficiencia de la Reforma; frente a la explotación de una, la libertad de la otra; frente a la violencia institucional, la violencia revolucionaria. No se puede comprender, por lo tanto, la idea de Reforma sin Hacienda, ni Hacienda sin Reforma. Finalmente, frente a ambas escrituras, que eran opuestas y la misma, una tercera que está en proceso de construcción, a la cual llamamos "otra ruralidad".

Por ello el inicial interés del presente artículo de abordar el proceso de la Reforma Agraria chilena a partir de las hipótesis comúnmente desarrolladas en cuanto a que esta Reforma fue precisamente la consecuencia de un abanico de urgencias constatadas en la mayor parte de los países de América Latina y cuyo foco central fue la necesidad de apurar la modernización productiva del sector agrícola, así como enfrentar los desafíos de reconfiguración de las relaciones de poder en el mundo del agro(Bellisario, 2013; Kay \& Pineda, 1998).

Es en este marco, ampliamente abordado por la literatura que ha estudiado las diversas reformas agrarias del continente, que nuestro traba- 
jo sugiere que el proceso observado muestra una interesante lógica de "palimpsesto"2, donde las fronteras del cambio histórico son más bien imprecisas y no terminan por definir realidades que todavía se encuentran en tensión en varias de sus dimensiones.

\section{Dimensión sociopolítica}

La Reforma Agraria marca un antes y un después en la Historia de Chile. Lo anterior lo podemos afirmar puesto que claramente el objetivo de su implementación, implicaba, fundamentalmente, poner fin a la Hacienda; estructura económica, social, productiva y cultural que precisamente había regido a Chile (como patria o reino) durante más de 400 años. La idea de Hacienda a la cual nos referimos, había sido definida por Recaredo Tornero en 1872 del siguiente modo:

"En Chile se designa con el nombre de Hacienda a una porción cualquiera de territorio cultivable en todo o en parte, siempre que su estensión esceda de treinta cuadras cuadradas. Como el valor de la propiedad rústica solo ha comenzado a subir desde 50 años a esta parte, resulta que el mayor número de nuestras Haciendas tiene una grande estensión de territorio, alcanzando algunas hasta dimensiones mayores que las de un departamento ${ }^{3}$. La Hacienda de la Compañía, por ejemplo, tiene 11,000 cuadras planas i 98,000 de cerros, i de las Canteras tiene 27, 181 cuadras cuadradas. En toda Hacienda existe un edificio más o menos estenso, llamado las casas, que sirve al mismo tiempo de habitación para el patrón i el mayordomo i de bodega o depósito para las mercaderías o herramientas. El gobierno interior de la Hacienda depende inmediatamente de sus dueños, pero no están sustraídas a la inspección i jurisdicción de las autoridades locales (SIC)’(Tornero, 1872, p. 427)

Precisemos que la Hacienda fue, en primer lugar, un sistema de producción agrícola orientado fundamentalmente a la comercialización de sus productos en el mercado externo. Este sistema productivo se sostenía sobre la base de una jerarquía social y política en cuya cúspide se ubicaba el hacendado (o Patrón), que era el propietario de las tierras y de la producción, y luego por los inquilinos, que eran, al, mismo tiempo, trabajadores y habitantes de sus tierras. Entre ambos existía una relación de producción que funcionaba claramente sobre una fórmula específica de intercambio y coexistencia. Así como el patrón proveía a sus inquilinos de terrenos para instalar sus ranchos, mantener una chacra, más algunas regalías, el inquilino le pagaba al patrón un canon y le ayudaba en los trabajos de la Hacienda. Este canon, sin embargo, para la tradición sociológica conservadora chilena no era un pago, sino más bien un tributo que el inquilino ofrendaba al patrón, quién, en su consumo y a través de rituales y fiestas (religiosidad popular), cumplía el rol de realización del valor del trabajo de los inquilinos. Además de los inquilinos, también eran parte de esta estructura productiva los peones, quienes eran contratados por los patrones, especialmente, du- 
rante la época de siembras, cosechas, matanzas o trillas, y se caracterizaban por ser una masa de personas nómades, sin ocupación fija, y que además de deambular y tener este trabajo agrícola temporal, lograban su subsistencia a través de pequeños robos (Salazar, 2000).

\section{Imagen $\mathrm{N}^{\circ} 1$ Hacienda de Colcura}

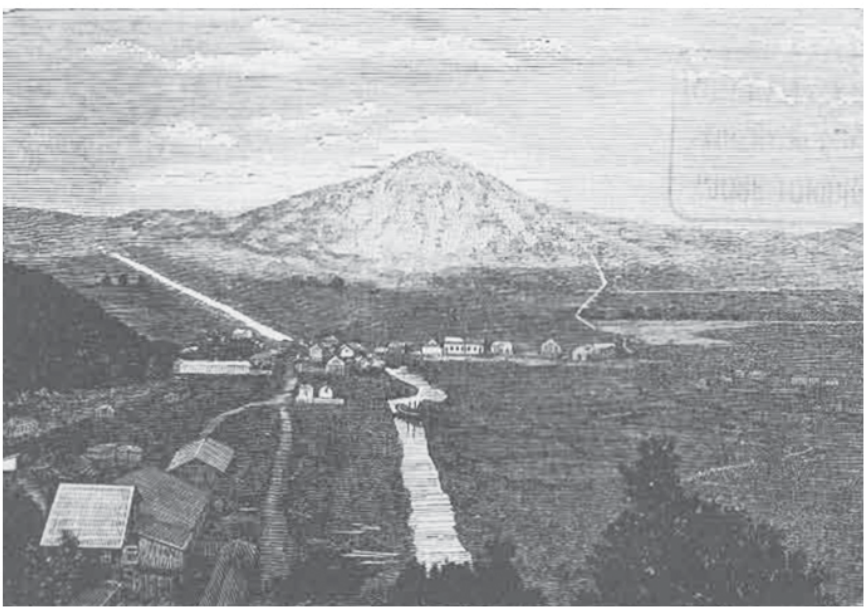

Fuente: (Tornero, 1872, pp. 432)

La Hacienda, en cuanto sistema productivo, pero también como estructura de dominación y subordinación, determinó la Historia de Chile hasta la segunda parte del siglo XX. Fue en ese momento que una serie de circunstancias históricas dieron lugar a la transformación de esa modalidad de tenencia. El instrumento de transformación de esa realidad fue lo que hoy precisamente conocemos como la Reforma Agraria. Ahora bien, la complejidad de estas transformaciones estuvo determinada por la propia diversidad de dimensiones que la Hacienda, como modelo, abarcó.

Por lo tanto, si la Hacienda tenía un proyecto socioproductivo (Bauer, 1975; Góngora, Mario, 1960; Kay, 1982; Salazar, 2000), la Reforma provocó cambios en ese proyecto. Si la Hacienda tuvo una dimensión sociopolítica, sea ésta como poder (Bengoa, 1988, 1990; Cáceres, Juan, 2007; Mellafe, 1981; Morandé, 1984), sea ésta como instituciones públicas territoriales (Cáceres, Juan, 2007; Castillo, Fernando, 2011; Illanes, María Angélica, 1993), la Reforma también implicó un cambio en esas relaciones de poder. Si la Hacienda tuvo una dimensión sistémica, como misión sui generis de modernidad, (Bauer, 1970; Morandé, 1984; Robles, 
2003; Salazar, 2009), la Reforma implicó una transformación también en esta dimensión de regulación de sus esferas de funcionamiento.

En rigor, los argumentos a favor de una Reforma Agraria comprendían no solamente una dura crítica a la ineficiencia productiva de la Hacienda - aspecto que trataremos en la sección correspondiente - sino también y muy fundamentalmente - se galvanizaron a partir de una crítica a la estructura misma de propiedad. Específicamente, la Reforma Agraria se presentó, en esta dimensión, como un juicio negativo a las relaciones de dominación y explotación que esa estructura de propiedad - o de apropiación - implicaba en la relación entre el patrón y sus trabajadores agrícolas (inquilinos y peones). Era la Hacienda, para los promotores de la Reforma, un signo de premodernidad que anclaba, en pleno siglo XX, a los trabajadores del campo chileno a un feudalismo como el del siglo X europeo. Por lo tanto, la transformación de estas relaciones de producción era, al mismo tiempo que económicamente necesaria, sociopolíticamente urgente. La expropiación y redistribución de tierras obedecía, en este contexto, a un intento de integración sociopolítico del campesinado.

El argumento socio-productivo, a saber, la ineficiencia productiva de la Hacienda, fue un argumento central en la Reforma Agraria chilena; sin embargo, para el resto de las reformas agrarias latinoamericanas, fue sobre todo el sentido sociopolítico, de libertad e integración del campesinado, el leitmotiv determinante de las expropiaciones y reparticiones.

"La estructura social de Chile se estabilizó sobre bases agrarias y la vida entera de la nación hubo de moldearse en relación con la tierra. Los dueños de ella mandaban, y a los que nada poseían correspondía obedecer. La condición de cada cual estaba determinada por el hecho de poseer o no poseer una Hacienda, o al menos de formar parte de una familia terrateniente. Posición social, ocupación, oportunidades, dependía principalmente de tal circunstancia. Habilidad, grado de educación, éxito en cualquier sentido, aun la adquisición de riquezas, significaban menos que el hecho de haber nacido en el círculo de quienes monopolizaban la tierra y sus productos”(McBride, Jorge, 1970, p. 31)

Esta verdad, que podemos llamar de naturaleza revolucionaria, que justificaba, política y socialmente a la Reforma, sin embargo, se enfrentaba también a otra verdad justificatoria del orden tradicional. Como bien describe la sociología conservadora chilena (Morandé, 1984), la relación hacendal entre el patrón y los campesinos, fue - visto desde esta otra perspectiva como la que permitió esta suerte de pax rural que caracterizó, a contrapelo de otras realidades latinoamericanas, a la sociedad chilena. Ahora bien, esta estabilidad fue fruto, precisamente, de esta relación de dominación entre hacendados y campesinos. Fue - según este enfoque histórico - "en el patrón” donde el inquilino encontró la realización del valor de su propio trabajo. Igualmente era en las fiestas que éste promovía y financiaba, donde se realizaba el ritual que daba sentido a sus existencias. 
Contrario sensu, fue "en el inquilino” donde el patrón encontró una misión, inclusive, civilizatoria. Ante la barbarie y la pobreza, la civilización y el desarrollo - y también como puente entre ambos - aparece el patrón. Como dato ilustrativo, así describía Menadier - editor del boletín de la SNA y experto agrario del siglo XIX al campesinado en 1869 -, en un informe para el Presidente de la República con motivo de la Exposición Nacional de Agricultura:

“En otro ejemplo, en 1862, un terrateniente escribía 'estudiando con ojo atento las capas inferiores de nuestros campesinos, lo que sobresale es su indolencia o falta de ambición para mejorar su pereza habitual'. Un incremento en el jornal solo conseguiría 'aumentar su habitual holgazanería’” (citado por Bauer, 1970, pp. 174-175).

Esta condición bárbara del inquilinaje, era, sin embargo, anulada gracias al patrón. Describe Claudio Gay al campesinado chileno, ahora a partir de una relación de subordinación:

“Delante de su señor, es bueno, honrado, inteligente, muy hospitalario, dotado de alguna malicia, respetuoso, no osando jamas entrar en su casa con sus espuelas y manteniéndose á cierta distancia para hablarle. A pesar de ser muy amigo del cigarrito no se atrevería nunca á fumar en su presencia aunque bastante alejado y obligado a esperar, a menos que no obtenga el permiso que viene a pedir [...]. Es en extremo reservado con su patrón a pesar de serle adicto, [aunque] no mirando jamas por sus intereses ni tomando su defensa y permanenciendo mudo ante las fechorías de un compañero, aunque este sea a veces su enemigo. Es este, necesario es confersalo, un sentimiento de buena inteligencia muy comun en esta clase, y que la naturaleza parece haberles inspirado para compensar su inferioridad respecto de sus señores.(SIC)”(Gay, 1862, p. 153).

$\mathrm{Si}$, como sugiere Laclau, el antagonismo se explica como la presencia del "otro" que me impide ser totalmente yo mismo (Laclau, 2002), en la lógica política de la Hacienda el "otro" campesino no es un antagónico, sino que es un otro necesario, en tanto son las limitaciones de ese otrocampesino las que le permiten la realización de la misión de clase del patrón. Y al revés, para el campesinado, especialmente para los inquilinos - nuevamente en la lógica hacendal - el patrón del fundo tampoco es un antagónico porque le permitiría a éste, en tanto equivalente simbólico en la realización del valor del trabajo, su propia realización.

Dos verdades excluyentes pueden convivir al mismo tiempo. Esto, de hecho, es lo que constituyen el inconsciente según Freud. Y fue La Hacienda, precisamente, como sostiene Bengoa, ese lugar donde "se gestaron los inconscientes de la cultura: los sistemas de subordinación y poder; los arquetipos permanentes respecto al trabajo, a la familia, a la moral, a lo bueno y lo malo; en fin, las bases culturales de la sociabilidad” (Bengoa, 1990, p. 142) 
La Reforma Agraria, en este sentido, vuelve excluyentes estas dos verdades; la de la explotación y la de la realización del otro. Y propio del inconsciente, esta revelación, por lo tanto, no fue posible gracias a un cambio de pensamiento, sino que fue empujada por la situación sociopolítica que la circunscribía. En Chile, el establecimiento de la cédula única y la relegalización del Partido Comunista (que tenía como objetivos políticos la sindicalización y la Reforma Agraria); fuera de Chile, las exigencias de cambio promovidas por la conjunción católica de la administración Kennedy (Alianza para el Progreso), la Iglesia Católica y la Democracia Cristiana, que permitieron una reconfiguraron del orden y valoración de estas verdades contrapuestas. El resultado fue un proceso continuo y en permanente agudización del sistema de propiedad, que redefinió el orden de las fuerzas políticas y el contexto de las relaciones de poder y producción en el campo chileno.

La Reforma nace, por tanto, dicho en jerga marxista, como un proceso de transformación a la situación de enajenación (o de inconscientes) en las que convivían los habitantes del mundo rural chileno. Su objetivo era la reconfiguración del sistema general de dominación y explotación que se vivía entre el patrón y sus inquilinos y peones. Esta transformación fue exitosa. La Reforma develó la situación de explotación y permitió una reconfiguración del orden sociopolítico. La bastaron 11 años, entre la llamada Reforma de Macetero de Alessandri de 1962 y el golpe militar que derrocó a Salvador Allende en el 73, para terminar con un sistema de siglos.

Y luego la pregunta es ¿que quedó de todo aquello?... pues precisamente el palimpsesto. Porque si la Reforma borró lo escrito en el campo, como Hacienda; la dictadura y su violencia contrarreformista borraron, y muy pronto, lo que se estaba empezando a escribir en el campo como Reforma y empoderamiento del campesinado. El decreto 208 sobre las asignaciones (y re-expropiaciones) de tierra, y las demás transformaciones al sentido y fondo de las políticas relacionadas con el campesinado, terminaron reconfigurando al campo. La Reforma fue fundamental en la Historia de Chile como cierre, no como apertura. La Reforma agraria puso fin a la Hacienda y su estructura de dominación de clase, pero no logró esa apertura emancipatoria - del campesinado propietario, cooperativo o revolucionario. Así el sujeto histórico mutó del hacendado, como eje de realización y mascarón de proa de la misión de la nación, al campesino, como eje de la Reforma y del saber hacer en el trabajo. Luego de la contrareforma, el nuevo sujeto histórico es el dueño del packing y el que sabe ya no es el campesino, sino que el técnico agrícola. Los trabajadores se han convertido, en el mejor de los casos, en obreros, y, en el peor, en una suerte de lumpen agrícola. La violencia conservadora fue eficiente en eso. La dictadura normalizó la re-expropiación, la precarización del trabajo en el campo, y la reconcentración de la tenencia de la tierra. Los sueños de propiedad del campesino volvieron a su inconsciente. La gran conclusión sociopolítica es que la Hacienda ya fue y la Reforma también. Pareciese ser que no hay espacios - ideológicos - para más cambios en el mundo rural. 
A la hora de las entrevistas esto se ve claramente (PNUD-Chile, 2008). De la Hacienda queda en algunas personas, sobre todo en las de más edad - ex inquilinos y ex hacendados - , dejos de nostalgia y de rabia. De la Reforma, quedan recuerdos de la efervescencia por los sueños, y también, de la violencia que marcó la época. Pero en general, lo que más queda en las personas del campo, es el rumor. Esa suerte de radiación de fondo de la gran explosión - que fue la Reforma -, y que dio origen al universo de lo que es actualmente lo rural; fundamental y pre formativa, pero, al fin y al cabo, un rumor.

\section{Dimensión productiva}

Desde la época de la economía política clásica, la tierra ha sido considerada un factor de producción clave de poder. Ahora bien, como es de toda evidencia, en las zonas rurales la tierra tiene por sí misma una significación de mayor complejidad. Por una parte, la tierra es precisamente el principal factor de producción, fuente de empleo y repositorio de riqueza personal. Pero, por otra parte, la tierra configura, define y regula tanto las relaciones de poder como así también la condición social de las personas; aspectos que se terminan definiendo normalmente de acuerdo a la tenencia de la tierra.En materia de desarrollo económico y productivo, como lo señalan Díaz y Órdenes (Díaz-Diego \& Delgado, 2016, p. 164), Chile intentó permanentemente controlar desde los años 30 sus reiterados eventos inflacionarios. Para ello, la estrategia económica siempre fue el establecer menos incentivos para las importaciones de manufacturas, intentando maximizar la lógica más bien autárquica de la economía nacional. Como relato de este proceso, siempre se sostuvo que el campo chileno debía garantizar las necesidades básicas del país.

Sin embargo, la realidad agrícola de Chile estaba muy lejos de cumplir este objetivo, y, muy por el contrario, no era posible ni el desarrollo ni la modernización del agro, producto, precisamente, de la escasa importación de insumos y maquinarias agrícolas desde el exterior. Tampoco era posible lograr el objetivo del ajuste real pagado por el consumidor interno; esto también como consecuencia del control de las exportaciones.

Como ya lo hemos descrito, el sistema tradicional de explotación agrícola que hubo en Chile fue el de la Hacienda, cuya característica esencial fue la alta concentración de tierras en pocas manos y amparado en una modalidad de trabajo de jornaleros y pequeños campesinos dependientes.

"El mecanismo agroestatal es simple: la Hacienda y la familia del propietario concentraban amplios recursos territoriales y, por ende, población que vivía y moría al interior del fundo. También controlaban la población minifundista y pequeños propietarios que dependían de sus favores. El llamado complejo latifundio-minifundio fue un sistema social cerrado y dominado por los hacendados”. (Bengoa, 1988, p. 165) 
A lo que nos estamos refiriendo es, a un sistema latifundista donde el minifundio funcionaba exclusivamente desde una perspectiva orbital, lo que termina impulsando una estructura agraria expuesta a una fuerte descompensación económica. Producto de esta realidad, comienzan a emerger, cada vez con más fuerza, argumentos a favor de una distribución más equitativa de la tierra, fundándose en la hipótesis de que existe una relación inversa entre tamaño de la explotación y productividad real de la tierra (Tejo, 2003). La realidad agraria chilena de la época era un buen ejemplo para probar esta tesis, ya que ella se caracterizaba fundamentalmente por un tipo de producción tradicional donde no había operado una modernización consistente e intensa. La consecuencia de ello era la existencia de tierras muchas veces subutilizadas o en estado permanente de barbecho.

Si a ello le sumamos el impulso del pensamiento desarrollista de los años 50 y 60, no tardaremos en comprender que para muchos el campo chileno comienza a ser visto como un complejo problema de política nacional, sobre todo si la perspectiva para definir su carácter de problema es la idea de desarrollo general del país (Díaz-Diego \& Delgado, 2016, p. 165). Esta constatación cada vez más frecuente, puso en evidencia un conjunto de escollos estructurales de gran magnitud para el desarrollo económico del agro: baja capacidad de inversión en insumos, una precaria capacidad autárquica, una baja proyección de mercado y, más grave aún, una muy débil contribución a la economía nacional.Precisemos que para el período del Presidente Jorge Alessandri ${ }^{4}$ el sistema latifundista concentraba el 78\% de la propiedad agrícola, la que estaba en manos del 7\% de los productores. Esto dejaba a los pequeños propietarios, quienes representaban un 37\%, con solo un 0,3\% de la superficie productiva nacional (Henríquez María Eliana, 1987, p. 63).

Ya era un hecho ampliamente asumido por los actores técnico-políticos de la época el que Chile llevaba prácticamente cuarenta años (de los años 30 a los 60) con una agricultura enfrentada a limitaciones cada vez más insoslayables. Dos razones claves explicaban sus complejidades; primero, la estructura altamente desigual de la tenencia de la tierra $\mathrm{y}$, segundo, el trato excesivamente favorable dado a la industria versus una actitud de descuido de la agricultura (Kay, 2002, p. 466). Por mucho tiempo, la propia política cambiaria y comercial terminaron favoreciendo a la industria y limitando el desarrollo de la agricultura; esto al fomentar las importaciones de alimentos, así como desalentar las exportaciones agrícolas.

Como bien sabemos, la Reforma Agraria es, ante todo, la acción organizada y diseñada para cambiar los sistemas de tenencia de tierra, buscando evitar las largas permanencias de un solo dueño (redistribución de la tierra)(Garrido, Guerrero, \& Valdés, 1988, p. 35). Para el caso chileno, ya la denominada Ley Matte, № 7.747 de 1943 - norma pensada con una orientación eminentemente de impulso económico para el país - en dos de sus artículos declara de utilidad pública las tierras que no hayan sido cultivadas o que estén mal aprovechadas, facultando al Presidente de la República para expropiarlas. Del texto podemos presuponer que el objetivo, en este 
caso, era el desarrollo de la agricultura como actividad. Sin embargo, aún no aparecía en el discurso la idea de justicia social.

Más tarde, en 1955, la Sociedad Nacional de Agricultura, SNA, comenzó a hacerse cargo del término de Reforma Agraria, pero señalando que "la verdadera Reforma Agraria consiste en adoptar medidas que fomenten la producción y que alimenten a los productores que demuestren capacidad para mejorar rendimientos y perfeccionar cultivos, uno de cuyos instrumentos fundamentales debe ser un régimen tributario de incremento de inversiones con beneficio para las tierras mejor cultivadas" (Garrido et al., 1988, p. 35)

En 1957, el economista Gunnar Myrdal afirmaba que: "las reformas agrarias tienen su significado en el marco de un plan nacional de desarrollo, no sólo como precondición para levantar la producción agrícola, sino primordialmente como una manera de quebrar los fundamentos de la vieja estructura de clases de una sociedad estancada” (Garrido et al., 1988, p. 35).

Para 1960, ya era cada vez más evidente el continuo debilitamiento de la producción agropecuaria y la urgencia de ofrecer mayores perspectivas de desarrollo para la clase media campesina; haciéndose más generalizada, de esta forma, la idea de una Reforma Agraria fundada en una redistribución efectiva de la tierra.

Es por ello que para la Escuela de estudios económicos para graduados $^{5}$ (ESCOLATINA, 1961) esta idea de Reforma Agraria debía incorporar cuatro fases bien precisas: a) redistribución de la propiedad territorial, b) créditos para la explotación adecuada de la tierra que ha sido objeto de redistribución, c) asistencia técnica a los nuevos propietarios para la mayor explotación de la extensión territorial que haya recibido como consecuencia de la primera fase de la reforma, y, d) asistencia social con el fin de que alcance más altos niveles materiales de la vida . Para la época, el programa de gobierno del Presidente Jorge Alessandri no incorporaba la idea de una Reforma Agraria. El tema de la agricultura era abordado desde la perspectiva de aspectos más bien crediticios, de riego o de eliminación de escollos económicos para los pequeños productores.

No obstante aquello, hubo recién comenzado su período presidencial algunos impulsos normativos sobre la materia. Ellos comienzan con la Ley $\mathrm{N}^{\mathrm{o}} 13.305$ de 1959 cuyo objetivo fue otorgar facultades extraordinarias para producir cambios en la tenencia de la tierra; sin que para ello se utilizase el apelativo de "Reforma Agraria". Estos avances normativos continuarán con el DFL N ${ }^{\circ} 76$ de 1960, el que nominalmente ya abordaba temas de colonización y Reforma Agraria. Posteriormente el DFL N ${ }^{\circ}$ 65, por su parte, abogó por la constitución y definición de la “unidad económica” en remplazo del minifundio o parvifundio.

Sin embargo, es claro que hubo un factor de política internacional que gravitó de manera muy relevante en esta materia. La Alianza para el 
Progreso, promovida por Estados Unidos, teniendo como modelo el plan Marshall aplicado en la Europa de Post Guerra, promovió la idea de que son precisamente las modernizaciones las que producen desarrollo económico, y es el desarrollo económico el que termina produciendo más democracia (Cardoso \& Faletto, 1996). Por ende, era fundamental promover cambios estructurales tanto en el sector rural como en el tributario (Garrido et al., 1988, p. 84)

En este marco, la Conferencia de Punta del este de 1962 convocó la participación de 20 países, entre ellos Chile, firmándose el pacto de alianza para el progreso. El compromiso fue la realización de reformas en los países convocados a fin de recibir desde EEUU la entrega de capitales por veinte mil millones de dólares en un plazo de diez años.

De esta forma, el objetivo 6 de la Carta de Punta del este señalaba: "Impulsar dentro de las particularidades de cada país, programas de Reforma Agraria Integral, orientadas a la efectiva transformación de la tierra donde así se requiera, con miras a sustituir el régimen de latifundios y minifundios por un sistema justo de propiedad de tal manera que, durante el complemento del crédito oportuno y adecuado y la asistencia técnica y la comercialización y distribución de los productos, la tierra constituye para los hombres que la trabajan, base de su estabilidad económica, fundamento de su progreso, bienestar y garantía de su libertad y dignidad” (Ministerio de Relaciones Exteriores, 1962, pp. 79-113)

Desde el punto de vista institucional, se crea en el gobierno de Jorge Alessandri, en el año 1962, la Corporación de la Reforma Agraria (CORA), a la cual en el año 1967, en el gobierno de Eduardo Frei Montalva, se le confieren nuevas atribuciones para consolidar una estructura burocrática acorde a las exigencias de este proceso. Con ello se buscaba fundamentalmente la incorporación de la población rural al proceso de desarrollo nacional y una mayor eficiencia en la producción. Lo anterior para que el campesinado pudiese intervenir de mejor forma en la vida económica del país y, muy relevante, para que llegase a ser un consumidor importante. Como otro elemento clave se da un impulso también a la investigación agrícola a través de la creación de tres estaciones experimentales en el país (Santiago, Ñuble y Cautín).

En materia de expropiaciones de tierra, en el período del Presidente Alessandri se llegó a un número de 835.118 hectáreas; lo que no era considerado una cantidad relevante y, por ello, su apelación de "Reforma de Macetero”. Sin embargo, este período es significativo para cimentar la idea de Reforma Agraria tal como la entendemos en la actualidad, consignándose el impulso a los necesarios y urgentes cambios en la tenencia de la tierra, el apoyo al sector reformado, el incremento de la productividad y producción del sector, al desarrollo de las infraestructuras de servicios de apoyo y básicos para mejorar las condiciones de vida y el bienestar campesino.

Más tarde, para la campaña presidencial del año 1964, el tema de la Reforma Agraria ya estaba instalado políticamente como un tema de primer 
orden. Por este motivo, tanto Eduardo Frei Montalva ${ }^{6}$ como Salvador Allende Gossens $^{7}$ prometieron una drástica transformación estructural de la agricultura chilena.

Un cambio importante, en términos de la orientación del proceso a desarrollar, fue consecuencia de la inclusión de un planteamiento de orden más comunitario cuyas bases se describen en un estudio desarrollado por Julio Silva Solar y Jacques Chonchol (Silva Solar \& Chonchol, 1965).

Desde la perspectiva legal, el 30 de noviembre de 1964, el Presidente Frei presentó al Congreso un proyecto de Ley que reformaba el artículo 10 de la Constitución Política del Estado, promoviendo un cambio a la concepción del derecho de propiedad.

Artículo único.- Modifícase el № 10 del artículo 10 de la Constitución Política del Estado, en los siguientes términos: "El derecho de propiedad en sus diversas especies. La ley establecerá el modo de adquirir la propiedad, de usar, gozar y disponer de ella y las limitaciones y obligaciones que permitan asegurar su función social y hacerla accesible a todos. La función social de la propiedad comprende cuanto exijan los intereses generales del Estado, la utilidad y la salubridad pública, el mejor aprovechamiento de las fuentes y energías productivas en el servicio de la colectividad y la elevación de las condiciones de vida del común de los habitantes. Cuando el interés de la comunidad lo exija, la ley podrá reservar al Estado el dominio exclusivo de determinadas especies de propiedad. Nadie puede ser privado de su propiedad sino en virtud de ley general o especial que autorice la expropiación para que aquélla cumpla con la función social que el legislador califique”(Biblioteca del Congreso Nacional de Chile, 1965)

En aquellos años se acrecienta de manera muy definitiva el sentimiento de que la agricultura venía experimentando por largas décadas un retardo muy importante, lo que hacía urgente que el sector agrícola implementase cambios significativos y radicales. Para muchos, el gobierno de Eduardo Frei Montalva fue el que enfrentó el desafío político de la Reforma Agraria haciendo uso de una argumentación de tipo "estructuralista"; a saber se le argumentó al consumidor de clase media que la Reforma Agraria implicaría una mayor productividad y una mayor producción agrícola y, por ende, una disminución de los precios de los alimentos. Al proporcionarse tierras a los campesinos, quienes vivirían y trabajarían en ellas, la ineficiencia del sistema de fundos sería superada. Por su parte, a los dueños del comercio se les prometió que la Reforma ampliaría los mercados internos para productos manufacturados. Por ello los latifundistas no encontraron muchos aliados en el sector industrial y comercial al momento de concretarse las expropiaciones, las que en el período de Frei Montalva llegarían a 3 millones de hectáreas (Garrido et al., 1988, p. 102).

De esta forma, fueron creadas las condiciones para la discusión y posterior aprobación de la Ley Nº 16.640 sobre Reforma Agraria. 
“En resumen, al realizar la Reforma Agraria, perseguimos lograr la transformación de las estructuras de la agricultura en forma tal, que posibiliten la incorporación de todo el sector rural al desarrollo social, cultural, económico y político de la nación. Esto debe obtenerse mediante la substitución y reordenamiento de los actuales sistemas de propiedad y tenencia de la tierra por otros más justos que tengan por fundamento una redistribución de dicha propiedad, una reglamentación de los sistemas de tenencia y explotación que mediante el complemento del crédito oportuno y adecuado, la asistencia técnica, el mejoramiento de los sistemas de comercialización y distribución de los productos, mejoramiento acelerado de los niveles culturales de la población campesina y una acción vigorosa de conservación y acrecentamiento de la capacidad de uso de los recursos naturales renovables, a fin de que la tierra constituya para el hombre que la trabaja base de estabilidad económica, fundamento de su progresivo bienestar y garantía de la libertad y dignidad”(Biblioteca del Congreso Nacional de Chile, 1965, p. 15)

Posteriormente, en el período gubernamental del Presidente Salvador Allende Gossens ${ }^{8}$, los objetivos que fueron establecidos en materia de Reforma al agro pusieron énfasis en tres puntos principales: terminar con el latifundio, resolver el problema de la producción y promover la participación campesina.La gestión en materia de Reforma Agraria en el período del Presidente Allende se estructuraba en la observación política de que la gestión del Presidente Frei no se habría orientado correctamente al objetivo de proveer una mayor justicia social, sino más bien había puesto sus esfuerzos esencialmente en los temas concernientes a la "modernización de la agricultura”. Es por esta razón que a juicio de ciertos dirigentes de la Unidad Popular, el nuevo objetivo debía ser la construcción de "una nueva agricultura, incorporando a los campesinos como actores sociales a través de los consejos campesinos” (Gazmuri, 1971, p. 36).

En el marco de este nuevo impulso reformista, se preveía la expropiación de 3.000 a 4.000 latifundios, lo que implica un desafío económico de gran magnitud. Como lo afirma el líder del Movimiento de Acción Popular Unitaria (MAPU), Jaime Gazmuri: “un problema es eliminar el latifundio, el otro problema es qué agricultura hacemos de reemplazo. Si hacemos una agricultura de reemplazo, ésta debe ser bajo la dirección del campesinado” (Gazmuri, 1971, p. 30).

La respuesta operativa a este dilema de política pública fue el reforzamiento de una concepción de tipo cooperativista como la que había sido prefigurada por Chonchol y Silva (Silva Solar \& Chonchol, 1965). La estrategia no era, por lo tanto, fortalecer la idea de propietarios individuales, sino de estructuras de trabajo colaborativo. "Aquí no estamos en una situación de propiedad privada y la empresa, en definitiva, pertenece a un grupo grande de trabajadores de la tierra. Nosotros creemos que esa es una fórmula útil en la mayoría de los casos de las tierras que pasan a ser incorporados a la Reforma Agraria” (Gazmuri, 1971, p. 33) 
Paradojalmente, acompañando la dimensión cooperativista, también emerge la figura de la "hacienda estatal", donde el objetivo era configurar un sistema de estímulos a los trabajadores, no como propietarios, sino como trabajadores de un medio de producción de propiedad pública. Lo anterior, pensado sobre todo en aquellos predios que requerían una mayor capitalización, como era el caso de las empresas exportadoras agrícolas tales como las del vino, empresas ganaderas, etc.

A pesar del término abrupto de la experiencia de la Unidad Popular, ya era un hecho que en 1973 el orden latifundista, como lo habíamos conocido una década antes, había terminado. Se habían expropiaron en total 9,6 millones de hectáreas en el país y se había dado inicio a un proceso de transformación de la agricultura cuyos cambios persisten hasta el día de hoy; cambios que han estado regulados por objetivos de naturaleza eminentemente económica.

Como lo declarase el General Mendoza en representación de la junta militar en la feria Internacional de Santiago (FISA) de fines del año 1973, la nueva política agraria estaría regulada por objetivos eminentemente de "producción y de productividad” (Garrido et al., 1988, p. 151); por lo tanto no era posible una vuelta al pasado. Esta aseveración explica que la derogación de las disposiciones que permitieron la Reforma Agraria, sólo fue posible el año 1978 (DFL 2247) ${ }^{9}$.

La dictadura militar resolvió con pragmatismo económico esta vorágine de cambios que la Reforma Agraria había iniciado en Chile. No fueron aspectos de orden ético-social los que inspiraron esta actitud, sino más bien la búsqueda de una supuesta eficiencia agrícola. Con ello se optó por distribuir un porcentaje de las tierras entre nuevos propietarios, pero despojándolos del soporte de servicios y de asistencia técnica que permitiese que esta actividad gozase de viabilidad en un mundo donde los mercados internacionales cobraban una mayor relevancia.

De esta forma, nuestro palimpsesto siguió dibujando las diferencias entre un nuevo mundo de propietarios campesinos, que las más de las veces se encontraron desprovistos de apoyo, asistencia técnica, incentivos, reglas claras; y otro mundo de actores "empresarios", plenamente instalados en el proceso de modernización de la agricultura y con gran capacidad de adaptación al dinamismo de las condiciones de mercado.

Aún en nuevas condiciones de inclusión y exclusión propias de la sociedad y de la economía chilena actual, el mundo rural sigue reproduciendo una yuxtaposición de relatos que precisamente es distinto al tono del esquema homogéneo y normativo de la Hacienda o del espíritu reformista. De cierto modo lo que hoy se escribe, mezcla las caligrafías de ambos procesos, donde la continuidad está dada nuevamente por la asimetría de sus protagonistas. 
En esta misma dimensión, otra asimetría relevante es la relativa al peso de la idea de modernización agrícola versus la idea de una mayor justicia social. La revisión histórica descrita muestra la compleja convivencia entre ambos desafíos, orientándose, más bien, a una mayor importancia del impulso productivista. Lo anterior, ya sea por una idea global de desarrollo, ya sea por una efectiva convicción incrementalista, o, ya sea por la cada vez más difundida idea de que es el desarrollo económico el que produce más justicia social a modo de una especie de spillover.

\section{Dimensión socio - cultural}

La importancia que adquiere la dimensión cultural en esta discusión tiene relación con la pregunta: ¿Cuál es el énfasis que puso la Reforma Agraria, en cada una de sus etapas, en el componente reproductivo ${ }^{10}$ de los habitantes de los territorios rurales? La razón para esbozar esta interrogante se debe a que cuando se habla de la Reforma Agraria en Chile no existen dudas acerca de su rol productivo; sin embargo, al observar a esta Reforma desde la perspectiva reproductiva de los sujetos rurales no es tarea simple reconocer sus alcances y orientaciones, sin que de por medio se superponga el esfuerzo que esta Reforma puso en el fortalecimiento del rol político y empresarial del campesinado.

Para entender esta situación, es relevante poner en un contexto socio histórico a la Reforma Agraria en Chile. En efecto, ella se inscribe dentro de un proceso conocido como "nuevas teorías del desarrollo y la modernización” (Larraín, 2001, p.14), las cuales apuntaban, tal como lo señala Jorge Larraín "[al] desmantelamiento de las tradicionales identidades culturales agrarias y su remplazo por valores e instituciones modernos” (ídem). Razón por la cual el lugar de la cultura, tal como prosigue este autor "se redujo al elemento normativo de la transformación social y económica” (Ídem). La situación descrita da cuenta de que la Reforma Agraria, desde su génesis, puso sus énfasis en relevar la importancia de la promoción hacia la modernización productiva. Sin embargo, no podía perder de vista las precarias condiciones de vida del campesinado y de los habitantes de los sectores rurales. Sobre todo, una vez alcanzado el poder por parte de la Unidad Popular. Constatación que hace Jacques Chonchol al describir el contexto de la calidad de vida de los habitantes de estos sectores, señalando:

“[...] la mayor parte del campesinado vivía en condiciones sociales muy inferiores al resto de la población: mientras en 1960 el analfabetismo afectaba al 12\% de la población urbana, se extendía al 35\% de la población rural: el 61\% de las viviendas campesinas eran ranchos o chozas y en materias de salud existían enormes diferencias entre las posibilidades de las poblaciones urbanas y de las poblaciones rurales. La legislación sobre sindicalización campesina era tan restrictiva que menos del $2 \%$ de los trabajadores del agro pertenecían a alguno de los escasos sindicatos existentes”.(Chonchol, 1994, p. 289). 
La pobreza, la marginalidad y la exclusión social se han transformado (previo, durante y post Reforma Agraria) en categorías hegemónicas desde las cuales se ha abordado "la cuestión social” de los campos chilenos. En la práctica esto ha significado que muchos de los esfuerzos públicos orientados a este sector hayan fijado la mirada en las condiciones de miseria de los habitantes de estos territorios.

La aproximación teórico - práctica a la situación descrita, en el contexto de la Reforma Agraria en Chile, estuvo puesta principalmente en la teoría de la marginalidad; la cual fue asumida como la estrategia para abordar las condiciones de miseria que vivían los habitantes de los sectores rurales por parte de la acción política de Eduardo Frei Montalva y, luego, durante el mandato de Salvador Allende Sin embargo, es necesario precisar que la marginalidad era un tema central de la agenda pública que apuntaba a la incorporación a los beneficios de la modernidad de masas marginales de Chile, por lo que previo a la Reforma Agraria no existía una distinción entre la miseria rural y la miseria urbana.

A pesar de lo anterior, las políticas que apuntaban al mejoramiento de la calidad de vida de los sectores excluidos del proceso de modernización, en combinación con la política de la Reforma Agraria, fue una importante oportunidad de centrar la mirada en las necesidades específicas que enfrentaban los sujetos rurales.

Ahora bien, es necesario precisar que los sujetos a los cuales se orientaba la Reforma Agraria eran solamente los campesinos y no la totalidad de habitantes de los sectores agrarios de aquellos años ${ }^{11}$. De esta manera, el trabajo que se impulsó apuntó solamente a fortalecer las condiciones de vida de los actores y sujetos que eran parte del movimiento campesino, a través de entrega de herramientas materiales y culturales, que les permitiera a éstos el paso de inquilinos a actores centrales para el desarrollo de los territorios rurales agrarios (Garretón, 2009).

De este modo, el contexto histórico de la Reforma Agraria pregonaba dentro de su quehacer la transformación de las estructuras productivas y de la sociedad rural en su conjunto(Canales, González y Alderete, 1994); materializándose lo anterior a través de políticas públicas que se focalizaron en suplir la carencia de recursos para la satisfacción de necesidades básicas, conjuntamente con la entrega de herramientas para la participación e integración cultural (Ídem). Es desde esta perspectiva que este enfoque dio lugar a una propuesta de promoción popular que articuló tanto la Reforma de la tenencia de la tierra, como también la alfabetización y todos los medios al alcance para el tránsito desde la exclusión "civilizatoria” del fundo y lo rural, hacia la cultura y la economía nacional. Desde otra vereda, muy cercana en lo social y en lo espacial, pero muy lejana en lo conceptual, esta perspectiva se vincula con las teorías de la "opresión de la conciencia" de los mundos rurales que analizó e intervino Paulo Freire en sus campañas de alfabetización reflexiva de los campesinos chilenos. En la práctica, las energías puestas para moderni- 
zar a los campos chilenos, específicamente a los sujetos campesinos, buscaron generar estrategias que permitieran:

"Preparar a los campesinos para sus nuevas funciones empresariales y darles en la práctica un sentido cooperativista. Además, permitía ver las posibilidades de incorporación de nuevos campesinos de las zonas vecinas de predios retomados como consecuencia del proceso de intensificación de la explotación” (Chonchol, 1994, p. 292).

Lo expuesto, pone en evidencia que estos esfuerzos, al estar puestos principalmente en la modernización productiva, significaron en la práctica la existencia de "una masa rural no beneficiada”, lo cual tal como lo relata Jacques Chonchol, trajo consigo la emergencia del descontento por parte de los habitantes de estos territorios, quienes, por primera vez, tuvieron la posibilidad de mejorar sus condiciones de vida. Frente a esta situación el programa de gobierno de la Unidad popular propone modificar la estructura de la tenencia de la tierra y el fin del latifundio con el objeto de promover nuevas relaciones económicas y sociales en los campos chilenos.

Otro aspecto relevante en lo que respecta a la dimensión cultural de la Reforma Agraria es la importancia que adquiere durante ese período el tema de las condiciones de habitabilidad rural. En primer lugar, debido a que un punto central para ésta es la entrega de tierras a los campesinos y las transformaciones de sus condiciones precarias de vida. Esta política pública, a pesar de estar orientada directamente a la modernización del sector productivo agrícola, incluye dentro de su programa el derecho a la propiedad familiar (una casa y un huerto), lo cual, durante los años de implementación generó una estructura habitacional asociada a la Reforma implementada. Los campesinos, por tanto, fueron los principales beneficiados por la política que apuntaba a la expropiación de los latifundios para ser repartidos entre los trabajadores vinculados a la producción agrícola (pequeños y medianos agricultores, minifundistas, empleados, inquilinos, medieros, entre otros) ${ }^{12}$.

Otra de las tensiones que se generaron en la sociedad rural a partir de la implementación de la Reforma Agraria, es la centralidad que cobró el hombre como proveedor y sostenedor de la familia rural (Tinsman, 2016). El lugar de la mujer en el modelo productivo agrícola de la década de los '60 estaba centrado en la labor que desarrollaba el inquilino dentro del fundo, el cual en su condición de trabajador recibía compensaciones que incluían su integración junto con su grupo familiar (mujer e hijos) ${ }^{13}$. El trabajo de la mujer se orientaba, por tanto, a trabajar en los predios de subsistencia ${ }^{14}$, que eran cedidos a cambio del trabajo del inquilino. Heidi Tinsman describe el contexto de la mujer previo y durante la Reforma Agraria señalando:

"[...] como sistema de trabajo familiar, el inquilinaje firmemente privilegiaba a hombres sobre mujeres. En la década de 1930, el 80 por ciento de los inquilinos y otros obreros agrícolas eran de sexo mas- 
culino, proporción que en la década de los 50 llegó al 95 por ciento. Si bien sus remuneraciones no eran altas, los hombres trabajaban de manera permanente o tenían derechos de uso sobre la tierra, gozaban de una retribución mucho más alta y mayor seguridad que las mujeres” (Tinsman, 2016, p. 63).

La modernización del campo, por lo tanto, establece una relación diferenciada entre hombres y mujeres, ubicando al hombre como trabajador y a la mujer como la encargada del cuidado de la familia y eje principal de las prácticas de reproducción; existiendo experiencias aisladas en el ámbito de la legislación laboral que dieron lugar, de modo fragmentado, a la introducción de la mujer como ciudadana y trabajadora. (Valdés y Araujo, 1999). Estas experiencias hacían eco a las normativas que se implementaban en la industria urbana y que resguardaban la lenta introducción de la mujer al trabajo asalariado.

A pesar de estos escasos esfuerzos, el lugar de la mujer durante la Reforma Agraria, es mayormente desvinculado del trabajo agrario asalariado, y su contracara fue el fortalecimiento de su rol reproductivo relativo al cuidado de las familiar, lo cual dejó invisibilizado el trabajo cotidiano y central que estas realizaban dentro de las producciones agropecuarias familiares.

De esta manera, la Reforma Agraria al estar orientada a la modernización productiva agraria pone como prinicipal impulsor al campesinado. Lo anterior implicó afrontar la creación tanto de nuevas relaciones económicas como sociales en el medio rural (Chonchol, 1994). Esto en la práctica significaba tal como lo hemos revisado, nuevas formas de habitar el campo, nuevos vínculos al interior de la familia, lo cual permearon la identidad de los espacios rurales de esos años.

Una de las fortalezas que tuvo este proceso de modernización es que al ser el sujeto campesino el encargado de llevar a cabo el proceso de Reforma Agraria, a pesar de las nuevas dinámicas modernas adquiridas por las prácticas sociales del campo, éstas eran asimiladas en función de una estructura social que deseaba estas transformaciones, y que en muchos casos las adaptaba a sus modos de vida. La modernidad, por lo tanto, era asumida como una posibilidad de mejorar las malas condiciones de vida de una gran parte de su población. Sin embargo, la contracara de esta focalización fue que dejó a muchos otros sujetos rurales en los límites de este nuevo contexto y sus beneficios.

Todos los esfuerzos realizados para el fortalecimiento del sujeto campesino, sufrirán una profunda escisión como consecuencia de la violenta instalación de la dictadura militar en Chile en el año 1973. Durante el régimen autoritario, los campesinos serán sujetos de persecución, sobre todo aquellos vinculados con el movimiento sindical que tuvo lugar durante la Unidad Popular. Lo anterior produjo un debilitamiento irreversible de las organizaciones campesinas hasta la actualidad, afectando al "sujeto campesi- 
no” quien ha quedado desdibujado de las subjetividades de los territorios agrarios.

Las consecuencias del palimpsesto, en lo concerniente a la dimensión socio cultural, implicaron profundas e irreversibles consecuencias en el campo chileno, principalmente debido a la anulación casi total que realizó la dictadura militar del actor central de la Reforma Agraria, el campesino; el que, dentro del proceso de modernización industrializado de los territorios agrarios actuales, deja de tener relevancia política y social en el desarrollo de los sectores rurales. El campesino se transformó más bien en una reminiscencia de un pasado promisorio que no alcanzó a ser.

La contracara del nuevo campo chileno es que en lugar de los campesinos surgieron los trabajadores asalariados, en su mayoría mujeres “temporeras” que, tal como lo dice su nombre, logran integrarse al mercado laboral como un importante contingente, pero su integración es intermitente y vulnerable, y su condición laboral no encuentra cabida ni respuestas de integración por parte de los postulados de la Reforma Agraria, ni tampoco ofrece respuestas de mejoramiento de sus condiciones de vida del actual proceso de modernización, quedando integradas de manera parcial y representando a un nuevo sujeto incidente de los sectores agrarios que no encuentra un relato histórico desde el cual instalar sus demandas en la actualidad.

Junto a lo anterior, en lo referente a los modos de habitar los territorios agrarios en la actualidad, ya no es posible encontrar a la Hacienda, pero tampoco a los asentamientos campesinos a los que aspiraba la Reforma Agraria. Lo que existe hoy es la conjunción de nuevos modos de vivir cada vez más urbanos por parte de los trabajadores agrarios, los cuales habitan en su mayoría en viviendas sociales construidas en las inmediaciones de los centros de las comunas con vocación productiva agrícola industrial globalizada y la cada vez más evidente concentración de grandes extensiones de tierras en manos de unos pocos empresarios agroindustriales; y, solo como elemento residual y en permanente amenaza de desaparecer, pequeñas parcelas de pequeños agricultores que se esfuerzan en comprender y adquirir las destrezas para poder integrarse en buenas condiciones al mercado agrícola nacional y global.

\section{Conclusiones y propuestas}

A cincuenta años de la promulgación de las leyes $\mathrm{N}^{\mathrm{0}} 16.640$ sobre Reforma Agraria en Chile y N ${ }^{0} 16.625$ sobre sindicalización campesina, el esfuerzo de recuperación de memoria de este acontecimiento histórico ha permitido reflexionar, con la sana garantía de la perspectiva que el tiempo otorga, sobre sus efectos materiales y simbólicos en la sociedad chilena.Puesto que existe una variada literatura que se ha interesado fundamentalmente en el valor historiográfico de este proceso y, también, desde la perspectiva de la ciencia política, en el rol y lógicas de acción de sus actores 
fundamentales, este artículo tomó más bien la opción de intentar observar la Reforma Agraria chilena desde otra óptica; a saber, la de sus paradojas y la de las múltiples escrituras yuxtapuesta que se han ido sucediendo desde el término de la Hacienda, la concreción de la Reforma Agraria y su historia posterior.

Desde la perspectiva de las paradojas, la primera y quizá la más significativa, es que la Reforma Agraria constituye el primer y más amplio esfuerzo de cambio estructural masivo en la sociedad chilena. Este esfuerzo, a pesar de que se le quiera inscribir en el contexto del tradicional clivaje izquierda-derecha, fue más consensual que lo que hoy se podría pensar. La Reforma Agraria termina siendo la consecuencia de un amplio acuerdo sobre la debilidad productiva del mundo rural y sobre lo perjudicial de la lógica intra-muros en la cual este mundo estaba confinado en el orden cultural y social.

La Reforma Agraria fue, así sea sólo en su dimensión productiva, la política de tres gobiernos con orientaciones distintas (Alessandri, Frei y Allende), así como también lo fue en cuanto imposición geoestratégica de Estados Unidos a través de la Alianza para el Progreso. La prueba más elocuente de esta realidad es que habiéndose creado, post Reforma, los prolegómenos de una agricultura distinta, la dictadura militar del general Pinochet no pudo ni quiso volver a una etapa pre Reforma. La Reforma Agraria provocó mayores consensos que lo que hoy algunos actores desean recordar; así sus verdaderos antagonistas fueron, en concreto y exclusivamente, los agricultores perjudicados.Ahora bien, el carácter paradojal de este proceso es que lo que termina concretándose en el tiempo no es necesariamente ni lo que pensaron quienes bregaron por la Reforma Agraria ni tampoco aquello que sus adversarios buscaron conservar. La Reforma Agraria no terminó constituyéndose en una economía rural de tipo cooperativa - y posiblemente este modelo tampoco iba a ser consistente aún sin experiencia de dictadura militar mediante -, ni tampoco fue el regreso de una contrarrevolución conservadora volcada a la reconquista nostálgica de los valores y prácticas del latifundio y de su estructura cuasi patriarcal. Hubo, por lo tanto, frustración de los reformadores y también frustración de quienes no pudieron retornar a una situación de antiguo régimen.

De esta forma, los resultados de la Reforma Agraria están muy lejos de parecerse a la voluntad de sus actores. Esta Reforma, en concreto, provocó la subdivisión de la tierra, y posteriormente ella facilitó una agricultura globalmente competitiva constituyéndose en "la madre" de la llamada actualmente modernización exportadora.

Una segunda paradoja es que a pesar de la innegable importancia histórica que la Reforma Agraria tuvo en el pasado - y sigue teniendo aún en cuanto a sus efectos productivos y sociales - se ha transformado en una realidad, por un lado, invisibilizada y, por otro, desvalorada. Lo anterior a la luz de los resultados del Informe PNUD presentados en este artículo (PNUDChile, 2008). 
Dadas estas paradojas, hemos querido ilustrar el proceso de la Reforma Agraria como el de un palimpsesto; a saber, como el de los viejos manuscritos que guardan en sí las huellas de una escritura borrada artificialmente y que insiste en ser reescrita.

Hablamos de un palimpsesto porque la Reforma Agraria terminó siendo fundamental en la Historia de Chile como un cierre, más que como una apertura definitiva. La Reforma Agraria puso fin a la Hacienda y su estructura de dominación de clase, pero no logró esa apertura integral del campesinado propietario, cooperativo o revolucionario. La dictadura militar terminó, posteriormente, normalizando la re-expropiación, la precarización del trabajo en el campo, y la reconcentración de la tenencia de la tierra. Los sueños de propiedad del campesino volvieron a su inconsciente. Por ello, la gran conclusión sociopolítica, es que la Hacienda ya fue, y la Reforma también. Por lo tanto, los espacios de cambio en el mundo rural parecen ser hoy mucho más inciertos.

También hablamos de un palimpsesto al hablar de las reescrituras constantes entre los idearios de modernización (en este caso agrícola) versus una sociedad de derechos cuya perspectiva es una aspiración a una idea de mayor justicia social. La convivencia entre ambos desafíos se ha inclinado regularmente hacia la dimensión productivista; lo anterior ya sea por una idea global de desarrollo, ya sea por una efectiva convicción incrementalista o ya sea por la cada vez más difundida idea de que es el desarrollo económico el que produce más justicia social a modo de una especie de spillover.

La pregunta que persiste es: ¿es necesaria una nueva Reforma Agraria?Las respuestas no son definitivas. Sin embargo, es de toda evidencia que el mundo rural ha cambiado significativamente; lo anterior puesto que la economía agrícola ha experimentado cambios de una envergadura que no pudieron ser previstos hace cincuenta años atrás.

Existiendo muchos ámbitos en los cuales hoy sería relevante interesarse, pensamos que a lo menos los siguientes subtítulos debiesen ser parte de una política consistente frente a lo que hemos denominado "una nueva ruralidad”.

a) Un tipo de Estado. Un Estado activo, no meramente regulador, capaz de orientar su acción sobre la base de normas de calidad en la gestión pública y capaz de observar prospectivamente los cambios que se seguirán sucediendo en el mundo del agro. Los efectos del calentamiento global en materia de reordenamiento (productivo y territorial) de la actividad agrícola, la urgencia en materia de desplazamientos de cultivos y tipos de cultivo, los efectos de la tecnificación del trabajo en la dinámica laboral agrícola, la exigencia de nuevos derechos laborales, la relevancia por la propiedad y uso del recurso agua, el surgimiento de nuevas exclusiones (v.g., temas de género), etc., exigen un Estado capaz de enfrentar, pertinentemente y oportunamente, este tipo de desafíos. Pensamos que en estos temas, fundamen- 
talmente aquellos relativos a los recursos naturales, surgirán los principales conflictos que una adecuada gobernanza de los territorios agrícolas deberá abordar.

b) Un tipo de política de Estado. La extrema sectorialización de la política pública ha mostrado en varios campos las restricciones de su operación, pero es en casos como el de la ruralidad donde sus efectos pueden ser más perversos. Una política que tienda a ruralizar lo sectorial y sectorializar lo rural, deja al mundo de la ruralidad confinado a una política tipo bonsay donde la jibarización y la fragmentación terminan convirtiéndose en su rasgo esencial. La Reforma Agraria fue, entre otros aspectos, el esfuerzo de política pública de reconstrucción del vínculo campo-ciudad. Pues bien, hoy hay que reinstalar los temas de la ruralidad en un contexto de política general.

c) Un tipo de acción de Estado. El año 1967 fue el año de la Reforma Agraria, pero también el año de la sindicalización campesina. Hoy en día, insistir en el fomento de la asociatividad en las zonas rurales es también ayudar a reconfigurar el ideal de ciudadanía. El mundo de la ruralidad no puede ser en exclusivo el mundo del emprendimiento agrícola y el mundo de los empleados del agro. Si hay una lección que nos deja la historia es que la tierra es fuente de una cultura cuya identidad ha sido el principal regulador del esfuerzo reformista en el campo. Es tiempo de colaborar para que ese discurso cultural se transforme también en un discurso ciudadano. 
Polis, Revista Latinoamericana, $N^{\circ} 47,2017$

\section{Notas}

${ }^{1}$ El autor Daniel Flores agradece el apoyo y financiamiento del Fondo Nacional de Ciencia y Tecnología del Gobierno de Chile (Fondecyt - Conicyt), proyecto Nº3150590

RAE:

Manuscrito antiguo que conserva huellas de una escritura anteriorborrada artificialmente(Real Academia Española, 2014)

${ }^{3}$ Un departamento es una unidad político-administrativa. En el siglo XIX el país se dividía en Provincias, Departamentos, Subdelegaciones e Inspecciones, cada una dirigida por un funcionario de gobierno. La referencia indica la enorme extensión de terreno que puede llegar a poseer el terrateniente.

${ }^{4} 1958-1964$

${ }^{5}$ El programa de graduados nace de una recomendación de la primera conferencia de Facultades de Ciencias Económicas de las Universidades latinoamericanas, segundo Congreso Universitario y primera Asamblea General de la Unión de Universidades latinoamericanas, celebrada en Santiago de Chile en 1953. Inició sus actividades en 1957 y, desde 1961, estuvo bajo la responsabilidad del Instituto de Economía y Planificación, dependiente de la Facultad de Ciencias Económicas de la Universidad de Chile.

${ }^{6}$ Candidato del Partido Demócrata Cristiano, quien fue elegido Presidente para el período 1964-1970.

${ }^{7}$ Candidato socialista del Frente de Acción Popular que agrupaba a socialistas y comunistas

8 1970-1973

${ }^{9}$ Derogación de causales de expropiación, asimilando las garantías de la propiedad agraria a las normas generales que rigen en general en materia de propiedad.

${ }^{10}$ Se definirá a lo reproductivo desde la perspectiva de Marx, en relación a la diferenciación y complementariedad que existe dentro del modelo económico capitalista entre la produccción, que apunta a la satisfacción de las condiciones para la vida humana (cantidad de productos, trabajo, etc.); y la reproducción, en relación a la generación de las condiciones necesarias para la producción: reproducción de los medios de producción (tierra, semillas, herramientas, etc.); de los productores; de las relaciones sociales entre los sujetos (Bernstein, 2012). En este trabajo se enfatizarán los elementos reproductivos relacionados con las relaciones sociales y los modos de habitar en los territorios agrarios.

${ }^{11}$ Debemos precisar que el campo en esos años era esencialmente expulsivo (migraciones) y excluyente (nada del orden moderno podía allí desarrollarse). Y entonces el crecimiento poblacional acelerado del ciclo demográfico, asociado a una estructura de tenencia de los recursos naturales y de lógica productiva no adecuada, implicaba que los campesinos debían necesariamente partir a la metrópolis en busca de la única vía de 
asalarización que, fin de cuentas, es esencialmente lo que iba a constituir socioeconómicamente la inclusión social.

${ }^{12}$ Así, la política de vivienda se hizo cargo de una demanda histórica del campo chileno, pero solo se cirscunscribe a un grupo acotado de beneficiarios, los campesinos. Frente a esto, las criticas por parte de los "otros" habitantes rurales no se hicieron esperar (Bengoa, 1987). La respuesta estatal frente a estas demandas fue la construcción de viviendas, lo que en muchos casos implicó la reubicación de la población del espacio rural al urbano, lo que en la práctica trajo consigo la implementación de una nueva organización habitacional (villorrios rurales) promovida por la CORA (Coorporación de la Reforma Agraria), lo que para estos sujetos permitió la respuesta a una demanda compartida de modernización del espacio rural; situación que modificó profundamente los modos de habitar los espacios rurales.

${ }^{13}$ En el año 1953 se legisla para todos los sectores productivos, incluido para el agrícola el pago de las cargas familiares por parte del empleador; lo cual fue muy resguardado por parte de los síndicatos de trabajadores agrícolas en formación durante esos años en los campos. (Valdéz y Araujo, 1999)

${ }^{14}$ Tierra que era cedida por el dueño del fundo a cambio del trabajo en sus predios. 
Polis, Revista Latinoamericana, $N^{\circ}$ 47, 2017

\section{Bibliografía}

Bauer, A. J. (1970). Expansión económica en una sociedad tradicional: Chile central en el siglo XIX, Revista de Historia 9, 137-235. Recuperado de: http://revistahistoria.uc.cl/wp-content/uploads/2011/10/bauerarnold-9.pdf

Bauer, A. J. (1975). La sociedad rural chilena: desde la conquista española a nuestros días. Santiago, Chile: Andrés Bello.

Bellisario, A. (2013). La reforma agraria chilena. Reformismo, socialismo y neoliberalismo, 1964-1980. Recuperado de http://repositori.uji.es/ xmlui/handle/10234/149906

Bengoa, J. (1988). Historia social de la agricultura chilena. Tomo I: El poder y la subordinación. Santiago, Chile: Ediciones SUR.

Bengoa, J. (1990). Historia social de la agricultura chilena. Tomo II: Haciendas y campesinos. Santiago, Chile: Ediciones SUR.

Bernstein, H. (2012). Globalización neoliberal y agricultura mundial. Dinámicas de clase y transformación agraria. México DF, México: Editorial M.A.Porrúa

Biblioteca del Congreso Nacional de Chile. (1965, 1967). Historia de la Ley 16640 Reforma Agraria. Recuperado de www.bcn.cl/ obtienearchivo?id=recursoslegales/10221.3/45903/1/HL16640.pdf

Cáceres, J. (2007). Poder rural y estructura social Colchagua, 1760-1860. La construcción del Estado y la ciudadanía desde la región, Valparaíso, Chile: Ediciones Universitarias de Valparaíso.

Canales, M., González, D., y Alderete, F. (1994). Pobreza y desarrollo Rural. Santiago, Chile: Universidad de Chile.

Castillo, F. (2011). La ordenanza de intendentes como fuente del conocimiento histórico: El caso de Antonio Álvarez y Jiménez. En Cáceres, J.y Cavieres E. (Eds.), Lecturas y (re)lecturas en historia colonial. Valparaíso, Chile: Pontificia Universidad Católica de Valparaíso.

Cervantes, M. (1871). El ingenioso hidalgo Don Quijote de la Mancha. Madrid, España: Sáenz de Jubera, hermanos editores

Díaz-Diego, J., y Delgado, M. Ó. (2016). Sujetos esquivados, memorias evadidas: sesgos antropológicos e historiográficos en torno a los dueños de la tierra durante la reforma agraria chilena. Historia Unisinos, 20(2), 163-177. 
ESCOLATINA. (1961). Some definitions and explanations of land reform. En seminario sobre Reforma Agraria y desarrollo económico, Santiago, Chile.

Garretón, M. A. (2009). Transformación de la matriz sociopolítica y desarrollo en Chile. Revista Diplomacia, Estrategia y Política, (9). Recuperado de http://www.manuelantoniogarreton.cl/documentos/04_09/ matrizesp.pdf

Garrido, J., Guerrero, C., y Valdés, M. S. (1988). Historia de la reforma agraria en Chile. Santiago, Chile: Editorial Universitaria.

Gay, C. (1862). Historia física y política de Chile. La agricultura. Santiago, Chile: Museo de Historia Natural de Santiago.

Gazmuri, J. (1971). Gobierno Popular, reforma agraria. Santiago, Chile: Ediciones Centro de Estudios agrarios UC.

Góngora, M. (1960). Origen de los “inquilinos” de Chile central. Santiago, Chile: Editorial Universitaria.

Henríquez M. E. (1987) . Reforma Agraria en Chile. Revista de Geografía Norte Grande, 14, 61-65. Recuperado de http:// revistanortegrande.cl/archivos/14/07_14_1987.pdf

Illanes, M. A. (1993). El Proyecto Comunal en Chile (fragmentos), 18101891, Historia (27), 213-329. Recuperado de http:// revistahistoria.uc.cl/wp-content/uploads/2011/10/illanes-mariaangelica-27.pdf

Kay, C. (1982). Transformaciones de las relaciones de dominación y dependencia entre terratenientes y campesinos en el periodo post-colonial en Chile, Revista Nueva historia, 2 (6).

Kay, C. (2002). Chile’s neoliberal agrarian transformation and the peasantry. Journal of Agrarian Change, 2(4), 464-501.

Kay, C., y Pineda, M. (1998). ¿El fin de la reforma agraria en América Latina? El legado de la reforma agraria y el asunto no resuelto de la tierra. Revista Mexicana de Sociología, 60 (4), 61-98.

Laclau, E. (2002). Misticismo, retórica y política. Buenos Aires, Argentina: Fondo de Cultura Económica.

Larraín, J. (2001). Identidad chilena. Santiago, Chile: LOM ediciones.

McBride, J. (1970). Chile: Su tierra y su gente. Santiago, Chile: Editorial Universitaria. 
Polis, Revista Latinoamericana, $N^{\circ}$ 47, 2017

Mellafe, R. (1981). Latifundio y poder rural en Chile de los siglos XVII y XVIII. Cuadernos de Historia, I, 87-105.

Ministerio de Relaciones Exteriores. (1962). Documentos Chile. Alianza para el Progreso. Carta de Punta del Este. Documentos internacionales.

Morandé, P. (1984). Cultura y modernización en América Latina: ensayo sociológico de la crisis del desarrollismo y de su superación. En Cuadernos del Instituto de Sociología Santiago, Chile: Pontificia Universidad Católica.

PNUD-Chile. (2008). Informe de Desarrollo Humano en Chile Rural. Santiago, Chile: PNUD.

Real Academia Española. (2014). Diccionario de la lengua española (23. ${ }^{a}$ ed.). Recuperado de http://dle.rae.es/?id=RYgSASM

Robles, C. (2003). Expansión y transformación de la agricultura en una economía exportadora: La transición al capitalismo agrario en Chile (1850-1930), Historia Agraria 29, 45-80. Recuperado de http:// www.historiaagraria.com/info_articulo.php?id=329

Salazar, G. (2000). Labradores, peones y proletarios. Santiago:, Chile: LOM.

Salazar, G. (2009). Mercaderes, empresarios y capitalistas. Chile, siglo $X I X$. Santiago, Chile: Sudamericana.

Silva Solar, J., \& Chonchol, J. (1965). Desarrollo de la Nueva Sociedad en América Latina. Recuperado de http://agris.fao.org/agris-search/ search.do?recordID=US201300471925

Tejo, P. (2003). Mercados de tierras agrícolas en América Latina y el Caribe: una realidad incompleta (Vol. 74). United Nations Publications. Recuperado de https://books.google.cl/ books?hl=es\&lr=\&id=E2X3qZ7Tc0gC\&oi=fnd\&pg=PA13\&d q=Tejo,+P.+(2003).+Mercados+de+tierras+agr\%C3\%ADcolas+en+Am\%C 3\%A9rica+latina+y+el+caribe:+una+realidad+incompleta.+Ediciones+CEPALGTZ\&ots=weMQ3Kh04L\&sig=z9RhhpNwyOE22CsfN8UDmlOFUM

Tornero, R. (1872). Chile ilustrado: Guía descriptiva del territorio de Chile, de las capitales de provincia y de los puertos principales Valparaíso, Chile: El Mercurio.

Recibido: 08.06.17

Aceptado: 03.07.17 